\title{
Differences in Motivation of Food Festivals Visitors - A View from the Czech Republic
}

\author{
Aneta KrajičkováA ${ }^{*}$, Martin Šauer ${ }^{A}$ \\ Received: April 03, 2018 | Revised: July 16, 2018 | Accepted: July 23, 2018 \\ DOI: $10.5937 / g p 22-17050$
}

\begin{abstract}
Gastronomy festivals are one of the fastest growing sectors of tourism and their importance for any destination is undeniable. The significance of the supply side attracts much more attention in research in contrast to the demand side in spite of the fact that knowing the customers and their motivation is the key for most aspects of realization and marketing of a festival. The main topics of this article are components of motivation to attend a festival that were obtained from self-administered questionnaires and categorized into dimensions of motivations. The dimensions are Taste, Experience, Social Status, Change, People, Family and Inspiration and they are studied in context of socio-demographic characteristics of the festivals attendees. This article compares two events held in the Czech Republic Pivni Fest in Pilsen and Valtice Wine Markets. The results show primarily a distinct perception of festivals in terms of dimensions Family and Experience and the influence of education and marital status on the motivation.
\end{abstract}

Keywords: differences in motivation; food tourism; food festivals; gastronomy motivation; tourism

\section{Introduction}

Festivals and special events are one of the fastest growing sectors of tourism and tourist attractions. They are suitable as devices for promotion and stimulation of national economies (Feslenstein \& Fleischer, 2003; Getz, 2000). Many of the festivities offer a unique experience and taking part in them is thus a good reason for travels. Despite the growing interest in this traveling fashion, a deeper understanding of the demand is needed since most research focuses on the supply side and the demand side remains neglected (Robinson \& Getz, 2014). Understanding the demand - for example in terms of motivation used as a central factor in understanding tourists (Chang \& Yuan, 2011) - allows identification of strengths and opportunities of the festivals (Lee \& Lee, 2001), contributes to effective positioning, and consequently creates a unique image, a capability to communicate the positive aspects to the customers, a distinction of the festival's brand from competing events, an improvement of the product and promotion (Smith \& Costello, 2009), and gaining an edge in the competitive marketplace (Weiler et al., 2004). Familiarity with the motivation also allows searching for differences within a specific section of tourism, such as gastronomic festivals which, at first sight, may seem homogeneous. The dramatic increase in both importance and number of festivals in recent years (Felsenstein \& Fleischer, 2003) and the associated internal differentiation call for more detailed data that could enable a proper use and success of the marketing mix and marketing strategies (Afonso et al. , 2018). According to Nicholson and Pearce (2001), the organizers should indicate how particular kinds of events attract different kinds of people and take necessary

\footnotetext{
A Department of Regional Development and Administration, Faculty of Economics and Administration, Masaryk University, Lipová 41a, 60200 Brno-střed, the Czech Republic; aneta.krajickova@mail.muni.cz

* Corresponding author: Aneta Krajičková, e-mail:aneta.krajickova@mail.muni.cz
} 
measures in these segments. This paper aims to identify the principal differences in motivations of the participants of two different gastronomic events held in the Czech Republic and to point out the relations between socio-demographic characteristics and the mentioned motivational dimensions.

\section{Gastronomy and tourism}

The role of food and beverage has been gaining in importance in today's tourist industry and will continue to be one of the major motivations for many people all around the world. According to the Secretary of State for Tourism (UNWTO, 2017) the primary motivation for about 6 million tourists per year is gastronomy and the local cuisine. According to the TIA study (2007), for example, up to 27 million people, that is $17 \%$ of all participants in leisure tourism, took part in activities associated with food or wine, where food accounts for $25 \%$ (McKerecher et al., 2008; Meler \& Cerovic, 2003) to 30\% (UNWTO, 2012) of total expenses, and the ratio is still growing. It has been assumed that food on its own serves only as a side resource of a destination, and thus does not have a sufficient power to compel people to travel. However, Oliviera (in Sánchez-Cañizares \& Lopéz-Guzmán, 2012) shows that local cuisine tasting can become the most important enticement of a destination, and food is therefore a significant component of its attractiveness and image (Chang \& Yuan, 2011; UNWTO, 2017). Gastronomy has become an inseparable part of a tourist's experience (Ignatov \& Smith, 2006; Fields in: Hall \& Sharples, 2002), a specific kind of meal, wine or a regional product is often the main motivation for visiting the destination (Hall \& Mitchell in Novelli, 2005).

The term "culinary tourism" was first used by Long (1998) to express the possibility to learn about distinct cultures through food and wine. More components were added later and the concept was broadened to include visits to both primary and secondary food producers, food festivals, restaurants, and other specific places (Hall \& Mitchell in Novelli, 2005), together with travels in search of unique gastronomic experiences, enjoying the prepared meals and drinks (Wolf, in Kivela \& Crotts, 2006). Some authors include the beverages here too (e.g. Hall \& Sharples, 2002), despite the fact that others recognize drink tourism as an independent category (Plummer et al., 2005; Bujdosó \& Szücs, 2012; Shanka \& Taylor, 2010; Weiler, 2004; Yuan, 2005; Jolliffee, 2007; Cheng, 2012; Allonso, 2011; Kraftchick et al., 2014).

Shorter and more frequent trips are becoming a trend in traveling (Egresi \& Kara, 2014). One of the forms this phenomenon takes are food and bever- age festivals - special events with a limited duration and a primary focus on wine and regional products most often set in wine regions (Bruwer, in Pan et al., 2013). Festivals are a unique way of fulfilling a desire to have a taste of specific kinds of meals, wines or regional products which has become one of the main motivations for travels (Hall \& Mitchell in Novelli, 2005). Some festivals, such as vintages and beer events, can be large and rather culture oriented. Food and beverage demonstrations are only one part of the whole and typically rich cultural program here. These events are often characterized by a rich cultural program. Besides that, other rather small-scale events are organized with emphasis on the presentation of particular regional products such as tastings of local spirits, grilling contests, traditional plum and blueberry dumpling fests, asparagus festivities etc. Specialized gastronomic events focused solely on food and drink tasting have a special place of their own too (Kotíková, 2013).

Numerous studies concentrating on food and beverage festivals have shown how festivals and tourism benefit each other (Smith \& Costello, 2009), and have identified the function and importance of festivals for the local community as well as for the region itself. People who otherwise would not consider visiting the destination may reconsider it thanks to a festival (Hall, 2007). It is a foundation for the image of the destination (Smith \& Costello, 2009), a part of the marketing strategy, a way of promotion, increasing attractiveness of local restaurants and wineries, boosting interest in original meals and beverages, spreading the awareness of the brand, providing education (Ellis et al., 2018; Hall \& Mitchell, 2005), and it supports loyalty towards the region (Hoffman et al., in Pan et al., 2013). Organizing gastronomic events contributes to the development of culture, leisure activities, cultural heritage, and invigorates the region economically (Smith \& Costello, 2009), stimulates the demand on related markets (Henderson, 2015), brings both economic and social benefits. It also brings communities closer together as these events create the environment for socializing, improve the quality of life of both locals and tourists, may reduce negative perception of the host community, and encourage further activity (Shanka \& Alamyio, 2012). 
Tourist motivations are complex and there are many potential motivations influencing a person in his decision to travel and in the choice of destination and other arrangements (Wall \& Mathieson, 2006). Motivation has been defined in different ways by numerous authors (Inkson \& Minnaert, 2018) for example as a physiological and psychological need - a lust that arouses, directs and integrates a person's conduct and activities (Iso-Aloha, 1982), a key factor and a driving force of all human behavior (Crompton, 1979; Pearce \& Lee, 2005). It answers the basic question of why people travel. Together with other features it leads us to specific similarities and differences in the behavior of certain groups, to the types of most popular activities, and to the characteristics of a tourist in general (Goeldner \& Ritchie, 2014). According to Cooper (2008) there are no two entirely identical individuals. The differences in their attitudes, perceptions and motivations influence, to a great extent, the decisions about their travels (according to Page (2015)), the differences themselves do not explain the reasons why people want to travel). At the same time, attitudes depend on the individual perception of the world. Besides, however clear and apparent the motivation is or can be, there are always hidden factors, or less evident reasons, related to the needs and wishes. To be aware of these specificities is a necessary prerequisite for the establishment of supply and its adjustment to the target markets. Hence, it is the basis for successful tourism practice (Goeldner \& Ritchie, 2014).

\section{Motivation at events}

The analysis of motivation factors is a prerequisite for effective planning, advancement, marketing, marketing segmentation, promotion, positioning, and long-term sustainability (Crompton \& McKay, 1997), not only because of the key role they play in the decision-making process (Park et al., 2008). These data are critical due to the growing competition and the development of events focusing not only on gastronomy. Crompton and McKay (1997) indicate the main reasons lying behind the effort to understand the motives of a festival's visitors. One of them is finding the key to the formation of supply, which means ensuring the program and the optimal presentation of the festival's elements in a way that it meets the identified needs, which are not universal (Chang \& Yuan, 2011). The second reason is closely related to the satisfaction that predetermines the viability of the festival. The third reason, then, is understanding the decision-making process. Park, Reisinger and Kang (2008) claim that motivation depends not only on the top- ic of the event, but is influenced by socio-demographic characteristics, the region and the location of the event as well. Crompton and McKay (1997), as well as Nicholson and Pearce (2001), have studied this topic earlier and show that there are similarities in motivation to participate in food and wine festivals.

We do not have a uniform methodology for identification and measurement of motivation. Researchers in food events mostly apply methods of evaluation of overall motivation, assessment of individual factors, or evaluation of motivation in dimensions (Park et al., 2008).

Crompton and McKay (1997), for example, use 31 individual factors in their study, which shows the diversity in visitors' motivation at food festivals as compared to other kinds of events. The main difference here, the study shows, is the desire for cultural exploration, novelty, and the recovery of equilibrium. Cela, Knowles-Lankford and Lankford (2007) reveal that the primary motivation is the opportunity to participate in the festival followed by the motivation to support, taste and purchase local food. Further, Shanka and Taylor (2010) study the discriminatory factors in visitors' groups; Hattingh and Swart (2016) see wine tasting, food consumption, relaxation, new environment, spending time with family, and watching shows of famous chefs as most important. Following the general framework of motivation by Shone and Parry (Hattingh \& Swart, 2016), they deduce that the major part of motivation can be explained by the aforementioned physiological motives.

According to Kim and Lee (2002), the use of push and pull factors works the best. Yuan et al. (2005) uses the same approach focusing on the pull factors related to the festivals and visitors, e.g. availability of parking spaces, services, program; and push factors like enjoying a day off, entertainment, socialization, and relaxation. Dodd et al. (2006) discover that the pull factors are more important for the visitors under 35 years of age. Smith, Costello and Muenchen (2010) imply that the push factors influence the overall satisfaction of a visitor only minimally, but, unlike the pull factors, they are more suitable for subsequent segmentation of tourists.

The evaluation based on the identified dimensions requires the identification of individual elements. It can thus be decided which dimensions and elements are more influential and contribute to the overall motivation, and so reveal their crucial/minimal impact (Park et al., 2008). Studies typically identify 5 to 6 dimensions of motivations derived from 19 to 34 elements. These dimensions are very similar to each other regardless of the theme or location of the event. Smith, Costello and Muenchen (2010) claim that the 
importance of key dimensions of motivation varies according to the type of festival, but the groups, in fact, remain the same. There is very little research on this topic in the area of food events.

Nicholson and Pearce (2001) identified following dimensions: event socialization, event novelty/uniqueness, escape, and family. The most important dimensions of motivation in Weiler et al. (2004), valid for the Australian Wine Festival, are cultural exploration, socialization with a trace of desire to interact with others, and event novelty, which includes the search for new experiences. This research corresponds with the research by Crompton and McKay (1997), where family togetherness and the recovery of equilibrium are least important. Using the concept of dichotomy, Yusal (in Smith \& Costello, 2009) linked 22 elements into the dimensions of event novelty and socialization, which are of more importance to the attendees who visit the festival repeatedly, and the dimensions of excitement/thrills, family togetherness, and escape. The study by Park, Reisinger and Kang (2008) focusing on first-time visitors identified the main factors which motivate the attendees of South Beach Wine and Food Festival in Miami Beach, Florida. These are, for example, taste, enjoyment, social status, change, meeting people, family and meeting experts. The first four are in this case the most important ones for the visitors. They explain a much greater part of the overall motivation, while the other three represent less prominent factors. Let us note that the most important among all separate elements appear to be those, which reflect the general theme of the festival, that is food and wine tasting, enjoying the environment and atmosphere of the festival, and an improvement of one's social status thanks to the participation in a unique and exciting event.

In spite of the already completed research, there still is a perceptual gap between the event organizers and the visitors' motivation for attending various festivals (Kim et al., 2002). Gastronomic events differ not only in their locations, but also in their focus on specific branches of gastronomy. The aim of this work is to identify the main factors that motivate the visitors of selected gastronomic events and to identify the main differences between them, with respect to the socio-demographic characteristics of participants. Two events of an international outreach were selected for the research with the intention to include as wide a range of products and attendees as possible. The events are the beer festival Pivni Fest in Pilsen (BFP) and Valtice Wine Markets (VWM).

\section{Methodology}

For the purposes of the research, a questionnaire was created based on the existing literature. It consists of two parts the first of which deals with socio-demographic characteristics of the attendees (Table 1). The second part focuses on motivation. The questionnaire was self-administered at each event throughout the day. It was not distributed at the entrance but to randomly selected visitors above 18 years old. Visitors, who agreed to fill in the questionnaire, were then asked about the place of their residence, so that tourists - as defined by UNWTO - could be identified. In case of doubt, individual questions were explained directly, the completion check was carried out right on the spot, all questionnaires where thus completed in 100\%. Questionnaires were created in Czech and English and distributed according to the preference of festival participants. It took approximately 5 to 7 minutes to fill in the questionnaire. A total of 260 questionnaires were obtained, 130 from each of the two events. The questionnaire was anonymous.

Twenty-eight individual elements from 7 dimensions were selected for the analysis. These were originally identified by Park, Reisinger and Kang (2008), and were adapted for the specific Czech environment and the studied events (Table 2). The elements were arranged at random, so that they do not evoke the subsequent di- mensions, and were assigned ratings "Completely Agree", "Rather Agree", "Rather Disagree", "Completely Disagree", each with a corresponding value from 1 ("Completely Agree") to 4 ("Completely Disagree") for use in the analysis. Owing to the chosen definition of answers, we can assign the average answer 2.5 with a neutral value. In the analyses of motivation, the lower value means higher significance, that is, the higher the value, the less do the participants identify with the statement, disagree with it or consider it unimportant.

A series of tests verifying the use of a one-way ANOVA test, which detects the statistically significant impact of socio-economic markers on individual dimensions of motivation, has shown that one of the preconditions - a normal distribution of data - was not satisfied in some of the data groups. Therefore, the statistical method, the Kruskal-Wallis test, was chosen as an alternative for the data that diverge from the normal type, together with the significance level $\alpha=5 \%$. The relationships between socio-demographic characteristics and motivations are shown in Table 3.

Pivnifest (BFP) is a beer festival held in the city of Pilsen. Its third year was organized on 6-8th May 2016 in a former Inwest community center. The three days were filled with a wide range of competitions for the audience, sporting events and other entertainment, a 
competition for the best bartender, concerts, and the World Giga Pizza Eating Championship.

Valtice Wine Markets are the oldest countrywide competition of wines with international participation, which builds on the tradition of the original wine markets in Valtice. It attracts thousands of visitors annually, this year it was 5,500 people. At the 49th Valtice Wine
Markets, held on 13th and 14th May 2016, the visitors had a chance to taste 727 samples of wines from 117 different wineries (Valtické vinné trhy, online, 2016). The event is known mainly for the high quality of the presented wines, and for the prizes that are awarded by the jury in each category or variety of wine, and which are highly valued among both experts and amateurs.

\section{Results}

As to the attendance of Pivnifest, there were more male $(61 \%)$ than female (39\%) visitors at the beer festival. This is most probably caused by the very nature of the festival and the fact that beer remains a prominent concern of men (Kraftchick et al., 2014). Such results, though, contradict the conclusions drawn by Pan, Sohn and Yuan (2013), who state that most participants of gastronomic festivals are women. The predominant age groups were people between 20 and 29 years (40\%) and between 30 and 39 years (32\%). The segment of visitors, thus, consisted of rather young individuals. Compared to Valtice Wine Markets, there were fewer visitors in Pilsen with university education $(42 \%)$, followed by the $32 \%$ of visitors with high school diploma (A-level equivalent) and a relatively high percentage of high-school educated attendees (25\%). The first-time visitors comprised the most numerous group, thanks to the rather short history of the festival. The visitors' country of origin was mostly the Czech Republic. 10\% of all attendees came from abroad, mostly from Germany, as the proximity in both space and tradition would suggest. Several of the interviewees arrived on their own, mostly, though, the visitors came with friends $(67 \%)$ or a partner $(19 \%)$.

For the purposes of the research, 130 participants of the wine markets were interviewed. Among them, there were 57 women (44\%) and 73 men (56\%). The most numerous age groups here were visitors between 50 and 59 (28\%), and 40 and 49 years (24\%), which corresponds with the research of Grybovych, Lakford and Lankford (2013), who proved that wine attracts older tourists. Almost 50\% of participants were university educated, and $32 \%$ of visitors were high school graduates (A-level equiv.), which - together with a high employment rate - corresponds with the findings by Robinson and Getz (2014). That is, that wealthier and more educated tourists are involved in food tourism. It is unsurprising that up to $89 \%$ of attendees came from the Czech Republic. The second largest nationality at the festival was Slovaks, mainly thanks to the close proximity of Slovakian border and the historical bonds. VWM attract not only new visitors (27\%), but maintain the loyalty of regular visitors as well. More than $30 \%$ of the survey participants have visited the markets more than 6 times. VWM are not the kind of event that could be attractive for individuals. It is more popular among families and groups of friends. Only $1 \%$ of participants arrived at the event on their own. An explanation of this phenomenon can be found in the statistics of marital status of the participants, as $70 \%$ of interviewees indicated they are married or live with a partner. The most common source of information about the event are friends, acquaintances, and family.

The dimension of experience, and mainly the individual element "to have fun", are most significant for the attendees at the beer festival in Pilsen. Together with the opportunity "to relax" and "try new meal/ beverage", it constitutes the three most prominent elements of motivation. Beer probably remains the primary motivation, which prevails over other features of the festival, such as good food, fun, and the program of the event. Dimensions that further contribute to the overall motivation are taste, family and change. The boundary value that add to the motivation is 2.5 . The remaining dimensions work in the opposite direction and thus do not represent motivational elements; here for example meeting new people, social status, and inspiration. This - and also the environment of the festival - makes it clear that it is not a place suitable for meeting professionals or establishing new contacts. The festival is not designed for this and its environment does not support any potential efforts for that. This is most likely caused by the other motivations to participate in the event that people prefer. The beer festival fulfills the motivations of the participants in terms of having fun and relaxation, and provides a convenient opportunity to enjoy the exceptional festival environment and to spend time with friends.

The dimension of taste seems dominant at the VWM. The two individual elements "to have my favorite meal/ beverage" and "to try a new meal/beverage" are identified as most important together with the element "to share experience with family/friends/partner during the festival" which comes under the dimension of family. It is an event that is attractive mainly for offering an opportunity to spend time with family and friends - the second most prominent dimension. The following 
Differences in Motivation of Food Festivals Visitors -

A View from the Czech Republic

Table 1. Socio-demographic profiles

\begin{tabular}{|c|c|c|c|c|c|}
\hline & & \multicolumn{2}{|c|}{ PivniFest Pilsen (BFP) } & \multicolumn{2}{|c|}{ Valtice Wine Markets (VWM) } \\
\hline \multicolumn{2}{|l|}{$n=$} & 130 & $\%$ & 130 & $\%$ \\
\hline \multirow{2}{*}{ Gender } & Female & 51 & $39 \%$ & 57 & $44 \%$ \\
\hline & Male & 79 & $61 \%$ & 73 & $56 \%$ \\
\hline \multirow{6}{*}{ Age } & under 20 & 6 & $5 \%$ & 1 & $1 \%$ \\
\hline & $20-29$ & 52 & $40 \%$ & 18 & $14 \%$ \\
\hline & $30-39$ & 42 & $32 \%$ & 24 & $18 \%$ \\
\hline & $40-49$ & 14 & $11 \%$ & 31 & $24 \%$ \\
\hline & $50-59$ & 15 & $12 \%$ & 37 & $28 \%$ \\
\hline & 60 years and more & 1 & $1 \%$ & 19 & $15 \%$ \\
\hline \multirow{3}{*}{ Origin } & The Czech Republic & 117 & $90 \%$ & 118 & $91 \%$ \\
\hline & The Slovak Republic & 5 & $4 \%$ & 12 & $9 \%$ \\
\hline & EU & 8 & $6 \%$ & 0 & $0 \%$ \\
\hline \multirow{3}{*}{ Marital status } & Single & 51 & $39 \%$ & 24 & $18 \%$ \\
\hline & With partner & 44 & $34 \%$ & 37 & $28 \%$ \\
\hline & Married & 35 & $27 \%$ & 69 & $53 \%$ \\
\hline \multirow{5}{*}{ Occupation } & Student & 15 & $12 \%$ & 8 & $6 \%$ \\
\hline & Employed & 109 & $84 \%$ & 108 & $83 \%$ \\
\hline & Unemployed & 2 & $2 \%$ & 1 & $1 \%$ \\
\hline & Retired & 3 & $2 \%$ & 12 & $9 \%$ \\
\hline & Other & 1 & $1 \%$ & 1 & $1 \%$ \\
\hline \multirow{4}{*}{ Education } & Primary education & 2 & $2 \%$ & 1 & $1 \%$ \\
\hline & High school education & 32 & $25 \%$ & 23 & $18 \%$ \\
\hline & High school diploma & 42 & $32 \%$ & 42 & $32 \%$ \\
\hline & University education & 54 & $42 \%$ & 64 & $49 \%$ \\
\hline \multirow{4}{*}{ Came with } & Alone & 8 & $6 \%$ & 2 & $2 \%$ \\
\hline & Friends & 87 & $67 \%$ & 84 & $65 \%$ \\
\hline & \begin{tabular}{|l|} 
Partner \\
\end{tabular} & 25 & $19 \%$ & 28 & $22 \%$ \\
\hline & Family & 10 & $8 \%$ & 16 & $12 \%$ \\
\hline \multirow{11}{*}{$\begin{array}{l}\text { Source of } \\
\text { information }\end{array}$} & Family & 3 & $2 \%$ & 21 & $16 \%$ \\
\hline & Friends & 66 & $51 \%$ & 83 & $64 \%$ \\
\hline & Promotional materials & 11 & $8 \%$ & 9 & $7 \%$ \\
\hline & Radio & 5 & $4 \%$ & 0 & $0 \%$ \\
\hline & Press & 0 & $0 \%$ & 2 & $2 \%$ \\
\hline & Internet (in general) & 15 & $12 \%$ & 5 & $4 \%$ \\
\hline & Social media & 23 & $18 \%$ & 1 & $1 \%$ \\
\hline & Web of the event & 5 & $4 \%$ & 0 & $0 \%$ \\
\hline & Personal email & 1 & $1 \%$ & 0 & $0 \%$ \\
\hline & Advertisement & 1 & $1 \%$ & 0 & $0 \%$ \\
\hline & Other & 0 & $0 \%$ & 9 & $7 \%$ \\
\hline \multirow{8}{*}{ Visits } & $1 \mathrm{x}$ & 74 & $57 \%$ & 35 & $27 \%$ \\
\hline & $2 x$ & 38 & $29 \%$ & 11 & $8 \%$ \\
\hline & $3 x$ & 18 & $14 \%$ & 2 & $2 \%$ \\
\hline & $4 x$ & 0 & $0 \%$ & 4 & $3 \%$ \\
\hline & $5 x$ & 0 & $0 \%$ & 8 & $6 \%$ \\
\hline & $6 x-10 x$ & 0 & $0 \%$ & 24 & $18 \%$ \\
\hline & $10 x$ and more & 0 & $0 \%$ & 15 & $12 \%$ \\
\hline & value: more times & 0 & $0 \%$ & 31 & $24 \%$ \\
\hline
\end{tabular}

Source: Own processing 
Table 2. Average values of the responses in the dimensions

\begin{tabular}{|c|c|c|c|}
\hline Question & Dimension & BFP & VWM \\
\hline \multicolumn{4}{|l|}{ Taste } \\
\hline 3 & To have my favourite meal/beverage & 1.708 & 1.285 \\
\hline 9 & To find things I am going to buy in the future & 3.038 & 2.238 \\
\hline 12 & To have a good meal and beverage & 1.592 & 1.738 \\
\hline 28 & To try a new meal/beverage & 1.438 & 1.154 \\
\hline & Average & 1.944 & 1.604 \\
\hline \multicolumn{4}{|l|}{ Experience } \\
\hline 4 & To satisfy curiosity & 2.177 & 2.169 \\
\hline 6 & To have fun & 1.338 & 1.438 \\
\hline 20 & To enjoy the festival environment & 1.646 & 1.469 \\
\hline 23 & To enjoy the program of the event & 2.223 & 2.438 \\
\hline & Average & 1.846 & 1.879 \\
\hline \multicolumn{4}{|l|}{ Social Status } \\
\hline 2 & To make my friends think I went to a great event & 2.931 & 3.046 \\
\hline 10 & To visit a place I can talk about & 2.500 & 2.092 \\
\hline 17 & To share experience after the event & 2.346 & 1.723 \\
\hline 27 & To gain popularity among family/friends & 3.246 & 3.446 \\
\hline & Average & 2.756 & 2.577 \\
\hline \multicolumn{4}{|l|}{ Change } \\
\hline 1 & To escape daily routine & 1.977 & 1.608 \\
\hline 11 & To relax & 1.408 & 1.531 \\
\hline 15 & To relive boredom & 2.969 & 3.354 \\
\hline 24 & To enjoy a day out & 1.762 & 1.608 \\
\hline & Average & 2.029 & 2.025 \\
\hline \multicolumn{4}{|l|}{ People } \\
\hline 8 & To observe people aroud me & 2.831 & 2.623 \\
\hline 13 & To meet new people & 2.585 & 2.446 \\
\hline 21 & To meet people with same interests & 2.300 & 1.946 \\
\hline 25 & To gain new profesional contacts & 3.262 & 3.192 \\
\hline & Average & 2.745 & 2.552 \\
\hline \multicolumn{4}{|l|}{ Family } \\
\hline 5 & To go to a new environment wit my family/partner/friends & 1.962 & 2.077 \\
\hline 14 & To spend time with my family/partner/friends & 1.562 & 1.369 \\
\hline 18 & To share experience during the event & 1.977 & 1.354 \\
\hline 22 & To enable my family/partner/friends to go to the event & 2.415 & 2.238 \\
\hline & Average & 1.979 & 1.760 \\
\hline \multicolumn{4}{|l|}{ Inspiration } \\
\hline 7 & To talk to profesionals & 3.100 & 2.508 \\
\hline 16 & To expand knowledge about gastronomy & 2.515 & 1.585 \\
\hline 19 & To meet a celebrity & 3.154 & 3.423 \\
\hline 26 & To gain new recepies/ideas & 3.031 & 2.500 \\
\hline & Average & 2.950 & 2.504 \\
\hline
\end{tabular}


Table 3. Results of Kruskal-Wallis test

\begin{tabular}{|l|c|c|c|c|c|c|c|}
\hline BFP & Taste & Experience & Social Status & Change & People & Family & Inspiration \\
\hline Gender & 0.6892 & 0.0066 & 0.4015 & 0.0708 & 0.1384 & 0.0140 & 0.4643 \\
\hline Age & 0.0858 & 0.6174 & 0.3837 & 0.6714 & 0.1549 & 0.5377 & 0.3511 \\
\hline Education & 0.1436 & 0.0831 & 0.1031 & 0.0002 & 0.0165 & 0.1694 & 0.3543 \\
\hline Marital status & 0.0617 & 0.0816 & 0.0147 & 0.0002 & 0.0275 & 0.6877 & 0.0588 \\
\hline Occupation & 0.0945 & 0.9744 & 0.6218 & 0.7284 & 0.9022 & 0.9691 & 0.1398 \\
\hline Visits & 0.4289 & 0.7078 & 0.8519 & 0.0622 & 0.5844 & 0.8999 & 0.2672 \\
\hline VWM & Taste & Experience & Social Status & Change & People & Family & Inspiration \\
\hline Gender & 0.6890 & 0.0881 & 0.4976 & 0.4426 & 0.6678 & 0.0116 & 0.5142 \\
\hline Age & 0.0020 & 0.5961 & 0.1613 & 0.2226 & 0.0962 & 0.3896 & 0.1704 \\
\hline Education & 0.8127 & 0.0789 & 0.1466 & 0.0703 & 0.2415 & 0.2115 & 0.0418 \\
\hline Marital status & 0.4170 & 0.7212 & 0.9075 & 0.8502 & 0.1611 & 0.4268 & 0.0559 \\
\hline Occupation & 0.0474 & 0.1419 & 0.6677 & 0.0953 & 0.7805 & 0.2523 & 0.1135 \\
\hline Visits & 0.4885 & 0.1156 & 0.2691 & 0.0949 & 0.3928 & 0.3990 & 0.2063 \\
\hline
\end{tabular}

Source: Own processing

ones, then, are dimensions of experience and change. Tradition, culture and tastings of new wine create a remarkable atmosphere, which greatly influences the whole festival experience. Family remains an important aspect here as well. However, a certain pressure can be noted on expanding one's social group, meeting people with the same interests as well as professionals, but, most importantly, share the experience both during and after the event. Similarly as in the case of the beer festival, the dimensions of meeting new people and social status does not have a motivational impact. The dimensions concerning professionals and inspiration received the boundary value 2.5 .

\section{Taste}

The dimension of taste represents a common feature of both studied festivals, and corresponds with the main theme of the events. In $97 \%$ of the responses, the visitors of the wine markets in Valtice agreed that taste is an important component of their motivation. What is also important is the fact that the option suggesting trying a new, unfamiliar meal is preferred over having a favorite, known one. This can be of help to the exhibitors and sellers, who can adjust their offer, so that it meets the visitors' desire to discover unconventional tastes. Despite the fact that the dimension of taste strongly motivates the participation, the element "to find things I am going to buy in the future" stands out. Its value for the attendees of BFP is 3.038, which means that they prefer present experience over future consumption. In reverse, the future consumption is motivational in case of VWM. The Kruskal-Wallis test has revealed an effect of age on the responses at the wine markets. Older age groups are less motivated by taste than by family. Younger participants seem to have opposite preferences. Due to the generally older age of the visitors, it can be assumed that the family and the time spent with family/friends will be gaining in importance as a reason for attendance.

\section{Experiences}

Experience represents a significant feature of the events under study and is an inherent component of all events of this sort. Even though the atmosphere of the festival can possibly become one of the main attractions, as is evident in the case of VWM, it remains negligible for the beer festival. On the other hand, the atmosphere is also defined by the participants and their willingness to involve in the program and expand their social connections. The complementary program of the event comes in place here, though, it does not belong among the major motivational factors encouraging participation. It is hard to say, whether it is because the visitors to BFP have no interest and time to dedicate to the program, or because the program was poorly designed and simply did not appeal to the attendees. One of the elements that could help increase the attendance is inserting a "moment of surprise" to the program, which would not only improve the atmosphere, but also provide a new tempting attraction. Within the dimension of experience at the beer festival, the average value of the responses of women is lower than of men, but the dimension still remains crucial for both genders.

\section{Family}

The dimension of family is the second most important in VWM, and the third in the BFP. It includes friends and partners - it is a dimension represented by the elements concerning spending time with friends, and possibly the specific option "to enable my family/friends to go to the event". This may be the implicit factor in both studied events. It can be expected that, for instance, there can be one person in a group traveling together who provides the other with the possi- 
bility to travel, be it in terms of transport or finances. This element, however, is not directly motivational. Family is a universal topic barely influenced by the socio-demographic characteristics and, given that it is not related with the theme of the event, its share in the motivation is very significant. Presenting the festival as a place for spending time with family, or making it accessible for all age groups, could increase its attractiveness. In contrast is the motivation of sharing experiences, which is one of the most crucial in VWM. Interestingly enough, the participants of the BFP are not similarly oriented on the festival experience, despite their emphasis on present consumption.

\section{Change}

Change is a general topic which represents the opportunity to arrive in a new environment and do something different than usual. It is not directly motivational either, but the effect it has on the participants should be considered. It is clear, of course, that people do not attend these events to kill time and out of boredom. On the contrary, they pick carefully which events to visit. The dimension of "change" positively contributes to the overall motivation. It is important especially when looking at the option "out of boredom". More than $50 \%$ of participants completely disagree here. In total, $79 \%$ express disagreement. $10 \%$ more of the participants agreed with this element at the BFP, as compared to the VWM. Another significant difference appears in the effort to "escape the daily routine". Education and the marital status also influence the motivation factors of the visitor at the beer festival. It has proven that change impacts singles more than couples, people with high school education more than people with a high school diploma (A-level) and university graduates.

\section{Inspiration}

Even though the dimension of "inspiration" ranks fourth among the results for VWM, its value lies on the borderline leaning towards the negative effect of motivation. Besides, this segment of motivations is perceived differently by people with high school and university education. The former care more about the mentioned elements. The average value of their responses differs in nearly 0.4 points. This dimension is not so significant at the BFP. An event of this kind, however, offers only to a limited extent the chance to find new ideas, recipes, and meet professionals. In general, it focuses on a different purpose. The chance of "meeting a celebrity" exists at both events, but it has no impact on the motivation, which is a significant finding for the organizers of events. This dimension is characteristic for the substantial differences. In addition to what is said above, all elements that are motivational or borderline cases for VWM appear insignificant in the case of the BFP.
Older age groups see "expanding knowledge" as more important than other groups. The impact of this element, though, is rather small on the whole. However, the gastronomic events are designed particularly for meeting chefs, gastronomy, wine and beer connoisseurs. It is surprising that the interest in meeting is so little favored. Park, Reiseinger and Kang (2008) arrive at a similar conclusion:

"Event organizers should also seek to further provide quality experience by highlighting the opportunities to exchange knowledge with food and wine experts, familiarize myself with caterers, meeting celebrity chefs, develop new cooking skills and increase food knowledge."

\section{People}

Meeting and observing new people and extending one's social network are the elements of another dimension. Given that most of the interviewees were accompanied by another person during the festival, it is unsurprising that the effect of this dimension is so low. The sole motivational factor common for both studied events is "to meet people with the same interests". It has more effect on the visitors of the VWM, mainly for its atmosphere. The anticipated impact of the marital status and the interest in meeting new people preferred among singles was confirmed at the BFP. Comparing the values of individual elements shows only marginal differences. It is thus possible to say, that the interviewees are not interested in expanding their social networks neither actively, nor passively by observing people in their surroundings. The family plays an important role in the motivation of the participants. Therefore, creating an environment which would facilitate communication and making new acquaintances would most probably not have a big effect.

\section{Social Status}

The least important component of motivation is the social status. Its significance decreases with older age. It is more relevant for singles and for students (rather than working people). As has been shown above, the motivation to spend time with family/friends is one of the most important ones. Within its dimension it exceeds all the other factors, which is especially evident in the case of the VWM. Reaching a higher social status is motivational for only a narrow group of participants. The above studied factors are undoubtedly more significant. Still, the option "to share experience after the event" appears to be in contrast with other elements of this dimension. This suggests that, even though the future consumption of presented products turned out to be rather insignificant, introducing the event to those who did not attend, or reminding to oneself the past visit is of great importance. 


\section{Conclusion}

This study compares the differences in motivations at the gastronomic tourist events in the Czech Republic, using the dimensions identified in a previous research by Park, Reisinger and Kang conducted at the South Beach Wine and Food Festival in Miami Beach, Florida. Comparisons of motivations are still a rather new way of research and, in spite of the similarities between the two selected events, this study reveals considerable differences in motivations. The organizers of the events can benefit from them in terms of adjusting the supply for the specific target market and creating an effective marketing strategy.

Some findings of socio-demographic characteristics correspond and appropriately follow up the previous surveys on the given topic. Their influence on motivation, though, shows that they need to be included in the study of motivations. The factors of education and marital status of the participants can be considered the most important. This should be taken into account as the participants with university education, and therefore belonging supposedly to the higher-income social groups, prevail at the gastronomic events. In addition, it appears that people are willing to travel longer distances to participate in an event. A study by Leones, Colby and Crandall (1998) shows that people traveling from farther spend more at the destination to "justify" the travel expenses.

The obtained results concerning motivations of firsttime and regular visitors can be contrasted with other studies. This research reveals that the repetition of visits at the festivals has no effect on any of the studied dimensions, as opposed to what e. g. Uysal (in Smith \& Costello, 2009) and Shanka and Taylor (2010) claim.

Differences in the perception of the event emerged, when comparing the dimensions of motivation. The beer festival is mostly seen as a place for entertainment and gaining new experiences and new knowledge, covered by a common theme - beer and its (rather present than future) consumption. In comparison, the taste and tasting of wine together with family and friends seems to be the main reason why visitors attend the Valtice Wine Markets. It is a place suitable for sharing experience and expanding one's knowledge of wine and wine culture. This is an aspect the organizers should emphasize more, even though the current marketing campaign focuses on history and significance of wine, and the general reputation of the exhibition.

The benefits of the article can be found in three areas. First, the paper presents another contribution to the analysis of the food and beverage festivals motivations. It follows research by Park et al. (2008) and its motivation classification based on the South Beach Wine and Food Festival. The results were confirmed by some of Park's findings, especially as regards the status of the most important motivations for participation in the festival. It turns out that the taste and the experience are among the most critical motivations across the type of festival and the environment in which the festival takes place (Europe vs the USA, developed and emerging markets). On the other hand, there are also different findings. Mainly family and social status play a different role. Both categories have differentiation potential in the diverse environments and cultures. In the Czech Republic, the importance of the family for the decision-making process is crucial. This is also suggested by Park's study and its geographical segmentation, respectively the characteristics of the European participants in the festival.

Secondly, the paper brings more light to the position of sociodemographic factors in the decisionmaking process of festival participants and their links to individual dimensions of motivation. For example, in the social status motivation dimension, we have pointed to an increase in the importance of this factor with the declining age of respondents. This finding suggests a possible strengthening of the social status dimension in the future. This development can also be enhanced by the economic development of the Czech Republic (from the emerging country to the developed country) and the simultaneous promotion of the concept of wellbeing and its associated changes of values (Inglehart \& Wetzel, 2005).

Finally, thirdly, understanding the tourists' motivation is crucial for precise and effective marketing, providing high-quality products and services that meet the needs and satisfy the wishes of the visitors, adjustments of supply etc. and the results of the analysis can be incorporated by organizers into their marketing strategies and communication activities, especially as regards the importance of the family motivation dimension.

With regard to the growing importance of gastronomic events, the usefulness of the results presented is rather straightforward. They represent an opportunity for the organizers to address new markets by putting emphasis on the features of the events that are most motivational. Relatively low number and respondents and the overall structure of the questionnaire are limitations of the research that need to be acknowledged, as they affect the possibility of generalization. Further research in this area is essential with respect to the developing tourism industry and the challenges that come with the gastronomic tourism itself. 


\section{Acknowledgement}

This research was supported by the Project MUNI/A/o994/2017 "Cities, municipalities, regions: management, processes and interactions in theory and practice" and the Project UNI/A/1101/2017 "Destination management from the perspective of management theory".

\section{References}

Afonso, C., Silva, G. M., Gonçalves, H. M., \& Duarte, M. (2018). The role of motivations and involvement in wine tourists' intention to return: SEM and fsQCA findings. Journal of Business Research, 89, 313-321.

Alonso, A. D. (2010). Opportunities and challenges in the development of micro brewing and beer tourism: A preliminary study from Alabama. Tourism Planning \& Development, 8(4), 4145-431.

Bujdosó, Z., \& Szücs, C. (2012). Beer tourism: From theory to practice. Academica Turistica, 103-111; 5.

Çela, A., Knowles-Lankford, J., \& Lankford, S. (2007). Local food festivals in Nor theast Iowa communities: A visitor and economic impact study. Managing Leisure, 12(2-3), 171-186. doi:10.1080/13606710701339470

Chang, W., \& Yuan, J.(2011). A Taste of Tourism: Visitors' Motivations to Attend a Food Festival. Event Management, 15(1), 13-23. doi:10.3727/15259951 1X12990855575024

Cheng, S., Hu, J., Fox, D., \& Zhang, Y. (2012). Tea tourism development in Xinyang, China: Stakeholders' view. Tourism Management Perspectives, 2-3, 28-34. doi:10.1016/j.tmp.2011.12.001

Cooper, C. (2008). Tourism: Principles and practice. Harlow, England: Prentice Hall Financial Times. $736 \mathrm{pp}$.

Crompton, J.L. (1979). Motivations for pleasure vacation. Annals of Tourism Research, 6(4), 408-424. doi:10.1016/0160-7383(79)90004-5

Crompton, J.L., \& McKay, S.L. (1997). Motives of visitors attending festival events. Annals of Tourism Research, 24(2), 425-439. doi:10.1016/so16o7383(97)80010-2

Dodd, T., Yuan, J., Adams, C., \& Kolyesnikova, N. (2006). Motivations of Young People for Visiting Wine Festivals. Event Management, 10(1), 23-33. doi:10.3727/152599506779364660

Egresi, I., \& Kara, F. (2014). Motives of tourists attening small-scale events: The case of three local festivals and events in Istanbul, Turkey. GeoJournal of Tourism and Geosites, 93-110; 7.

Ellis, A., Park, E., Kim, S., \& Yeoman, I. (2018). What is food tourism?. Tourism Management, 68, 250-263.

Felsenstein, D., \& Fleischer, A. (2003). Local Festivals and Tourism Promotion: The Role of Public Assistance and Visitor Expenditure. Journal of Trav- el Research, 41(4), 385-392. doi:10.1177/00472875030 41004007

Getz, D. (2000). Explore wine tourism: management, development. Tourism management, 23, 641-643.

Getz, D., \& Robinson, R.N.S. (2014). Foodies and Food Events. Scandinavian Journal of Hospitality and Tourism, 14(3), 315-330. doi:10.1080/15022250.2014.946227

Goeldner, C. R., \& Ritchie, J. R. B. (2014). Cestovní ruch: principy, př́klady, trendy. BizBooks. 545 pp.

Grybovych, O., Lankford, J., \& Lankford, S. (2013). Motivations of wine travelers in rural Northeast Iowa. International Journal of Wine Business Research, 25(4), 285-309. doi:10.1108/ijwbr-07-2012-0023

Hall, C.M. (2007). Wine tourism in New Zealand. Academia.edu.

Hall, C.M., \& Sharples, L. (2002). Food tourism around the world: Development, management and markets. Amsterdam: Butterworth-Heinemann. 373 pp.

Hattingh, C., \& Swart, K. (2016). The motives for visitors to attend a food and wine event in Cape Town and their satisfaction levels. African Journal of Hospitality, 1-14; 6 .

Henderson, J.C. (2004). Food as a Tourism Resource: A View from Singapore. Tourism Recreation Research, 29(3), 69-74. doi:10.1080/02508281.2004.11081459

Ignatov, E., \& Smith, S. (2006). Segmenting Canadian Culinary Tourists. Current Issues in Tourism, 9(3), 235-255. doi:10.2167/cit/229.0

Inglehart, R., \& Welzel, C. (2005). Modernization, cultural change, and democracy: The human development sequence. Cambridge University Press.

Inkson, C., \& Minnaert, L. (2014). Tourism management: an introduction. Thousand Oaks, CA: SAGE Publications. $432 \mathrm{pp}$.

Iso-Ahola, S.E. (1982). Toward a social psychological theory of tourism motivation: A rejoinder. Annals of Tourism Research, 9(2), 256-262. doi:10.1016/01607383(82)90049-4

Jollifee, L. (2007). Tea and tourism: Tourists, traditions and transformations. Channel View Publications. $261 \mathrm{pp}$.

Kim, K., Uysal, M., \& Chen, J.S. (2002). Festival Visitor Motivation from the Organizers' Points of View. Event Management, 7(2), 127-134. doi:10.3727/152599501108751533 
Kim, S., \& Lee, C. (2002). Push and Pull Relationships. Annals of Tourism Research, 29(1), 257-260. doi:10.1016/so160-7383(01)00043-3

Kivela, J., \& Crotts, J.C. (2006). Tourism and Gastronomy: Gastronomy's Influence on How Tourists Experience a Destination. Journal of Hospitality \& Tourism Research, 30(3), 354-377. doi:10.1177/1096348006286797

Kotíková, H. (2013). Nové trendy v nabídce cestovního ruchu. Praha: Grada. 208 pp.

Kraftchick, J. F., Byrd, E. T., Canziani, B. \& Gladwell, N. J. (2014). Understanding beer tourist motivation. Tourism Management Perspectives, 12(1), 41-47.

Lee, Ch. \& Lee. W. (2001). World culture expo segment charakteristice. Anals of Tourism Research, 28(3), 812-816. doi: 10.1016/So1607-789(oo)ooo71-2

Long, L.M. (1998), Culinary tourism - A folkloristic perspective on eating and togetherness. Southern Folklore 55(3). 181-205.

McKercher, B., Okumus, F. \& Okumus, B. (2008). Food tourism as a viable market segment: It's all how you cook the numbers!. Journal of Travel and Tourism Marketing, 25(2), 137-148. doi: 10.1080/10548400802402404

Meller, M. \& Cerovic, C. (2003). Food marketing in the function of tourist product development. British Food Journal, 105(3), 175-192. doi: 10.1108/00070700310477121

Nicholson, R. E., \& Pearce D. G.(2001). Why do people attend events: A comparative analysis of visitor motivation at Four South Island Events. Journal of Travel Research. 39(4), 449-460. doi: 10.1177/004728750103900412

Novelli, M. (2005) Niche Tourism: contemporary issues, trends and cases. Amsterdam: Elsevier, $263 \mathrm{pp}$.

Page, S.J. (2015). Demand: Why do people engage in tourism. New York: Routledge. 468 pp.

Pan, B., Sohn, E. \& Yuan, J. (2013). Who are the culinary tourists? An observation at a food and wine festival. International Journal of Culture, Tourism and Hospitality Research, 7(2), 118-131. doi:10.1108/ IJCTHH-04-2013-0019.

Park, K., Reisinger, Y., \& Kang, H. (2008). Visitors' Motivation for Attending the South Beach Wine and Food Festival, Miami Beach, Florida. Journal of Travel \& Tourism Marketing, 25(2), 161-181. doi:10.1080/10548400802402883

Pearce, P. L. \& Lee, U. (2005). Developing the Career Approach to Tourist motivation. Journal of Travel Research, 43(3), 226-237. doi: 10.1177/0047287504272020.

Pivnífest. (2016). Pivní festival Plzeň. Plzeň: Tos Production. [online] (cit. 2017-01-31). http://www.pivnifest.cz/\#0_nas.

Plummer, R. Telfer, D. Hashimoto, A. \& Summners, R. (2005). Beer tourism in Canada along the Wa-
terloo-Wellington ale trail. Tourism Management, 26(3), 447-458. doi: 10.1016/j.tourman.2003.12.002.

Robinson, R. N. S., \& Getz, D. (2014). Profiling potential food tourists: an Australian study. British Food Journal, 116(4), 690-706. doi:10.1108/bfi-02-2012-0030 Sánchez-Cañizares, S.M., \& López-Guzmán, T. (2012). Gastronomy as a tourism resource: profile of the culinary tourist. Current Issues in Tourism, 15(3), 229-245. doi:10.1080/13683500.2011.589895

Shanka, T., \& Alamyio, G. (2012). Motivations to visit Events/Festivals: An Exploratory Investigation. In Australian and New Zealand Marketing Academy Conference. Adelaide, South Australia, Australian and New Zealand Marketing Academy.

Shanka, T., \& Taylor, R. (2010). Discriminating Factors of First-time and Repeat Visitors to Wine Festivals. Current Issues in Tourism, 7(2), 134-145. doi:10.1080/13683500408667976

Smith, S., \& Costello, C. (2009). Segmenting Visitors to a Culinary Event: Motivations, Travel Behavior, and Expenditures. Journal of Hospitality Marketing \& Management, 18(1), 44-67. doi:10.1080/19368620801989022

Smith, S., Costello, C., \& Muenchen, R.A. (2010). Influence of Push and Pull Motivations on Satisfaction and Behavioral Intentions within a Culinary Tourism Event. Journal of Quality Assurance in Hospitality \& Tourism, 11(1), 17-35. doi:10.1080/15280080903520584

TIA: Comprehensive Culinary Travel Survey Provides Insights on Food and Wine Travelers (2007). USA: Travel Industry Association.

UNWTO. (2012). Global report on food tourism: AM Reports. volume four.

UNWTO. (2017). Second global report on gastronomy tourism: AM Report: volume sixteen

Vinné trhy. (2016). Valtické vinné trhy. Valtice. www. vinnetrhy.cz 2016-2017, 2016 (cit. 2017-04-01). http:// www.vinnetrhy.cz/wp-content/uploads/2017/o3/ Celkova-TZ-VVT-2016.pdf.

Vinné trhy. (2016). Valtické vinné trhy: Wimbledon mezi výstavami. Valtice. [online]. (cit. 2017-04-01). http://www.vinnetrhy.cz.

Wall, G. \& A. Mathieson. (2006). Tourism: change, impacts, and opportunities. 2nd ed. New York: Pearson Prentice Hall.

Weiler, B., Truong, M., \& Griffiths, M. (2004). Visitor profiles and motivations for visiting an Australian wine festival. Monash University, Faculty of Business \& Economics.

Yuan, J.J., Cai, L.A., Morrison, A.M., \& Linton, S. (2005). An analysis of wine festival attendees' motivations: A synergy of wine, travel and special events. Journal of Vacation Marketing, 11(1), 41-58. doi:10.1177/1356766705050842 